\title{
Comparing coping styles, personality traits, and resiliency in multiple sclerosis patients
}

\author{
Amir Mahdi Katani $^{\circledR}$, Shahnaz Mohammadi ${ }^{*}{ }^{\circledR}$, Zahra Davoodi $^{\circledR}{ }^{\circledR}$, Somaye Shahmoradi ${ }^{\circledR}$ \\ 1PhD Student of Clinical Psychology, Faculty of Medicine, Shahid Beheshti University of Medical Sciences, Tehran, Iran \\ ${ }^{2}$ Associate Professor, Department of Clinical Psychology, Kharazmi University, Tehran, Iran \\ ${ }^{3} \mathrm{PhD}$ Student of Family Counseling, Faculty of Medicine, Shahrekord University of Medical Sciences, Shahrekord, Iran \\ ${ }^{4}$ Assistant Professor, Department of Counseling Psychology, University of Tehran, Tehran, Iran
}

*Corresponding Author: Shahnaz Mohammadi, Associate Professor, Department of Clinical Psychology, Kharazmi University, Tehran, Iran. Tel: 021-86072738, Email: Smohammadi@khu.ac.ir

\begin{abstract}
Background and aims: Multiple sclerosis (MS) is a common neurological disorder with complex etiology, which is highly affected by psychological factors. These factors should to be identified to help patients with MS (PwMS). This study aimed to compare coping styles, personality traits, and resiliency in PwMS and healthy subjects.

Methods: In this case-control study, we selected 75 PwMS from the members of Tehran MS Society in 2016 as case group and 75 healthy subjects as control group. To collect data, we used the Ways of Coping Questionnaire (WOCQ), Big Five Factor Inventory-Revised, and Conner-Davidson Resilience Scale (CD-RISC). Multivariate analysis of variance (MANOVA) and independent T-Test were used to analyze the data.

Results: The results indicated that PwMS use emotion-focused coping styles more often $(44.53 \pm 9.13, P=0.008)$ and problem-focused coping styles less often $(39.84 \pm 5.79, P=0.001)$ compared to control group. Also, they showed higher scores in neuroticism $(32.10 \pm 4.80$, $P=0.001)$ and lower scores in extraversion and conscientiousness $(27.46 \pm 7.12, P=0.005$ and $32.98+ \pm 5.72, P=0.008$, respectively). The resiliency levels in these patients were also lower than healthy subjects $(68.13 \pm 13.90, P=0.021)$.

Conclusion: Our findings indicated that PwMS are more likely to use emotional coping strategies in stressful situations compared to healthy individuals. Moreover, data confirmed that a maladaptive personality configuration, which is specified by high neuroticism, along with low extraversion, conscientiousness, and agreeableness are somehow related to MS.

Keywords: Coping strategies, Personality traits, Resiliency, Multiple sclerosis, MS, PwMS
\end{abstract}

Received: 26 August 2020, Accepted: 31 August 2020, ePublished: 30 June 2021

\section{Introduction}

Multiple sclerosis (MS) is an autoimmune disease of central nervous system (CNS), which is specified by inflammation, demyelination, and neuronal degeneration (1). It is characterized by the occurrence of wide-spread lesions in the brain and spinal cord, which leads to a broad range of sensory, motor, cognitive, and neuropsychiatric symptoms (2). Some prevalent manifestations of MS include muscle weakness, visual loss or double vision, gait instability or ataxia, fatigue, pain, mood change (e.g., depression), loss of bladder control, sleep disorders, and sexual problems (3). Iran is well-known for its high prevalence of MS in the world with at least 30/100000 PwMS (4) and the prevalence has been incremental (5). In fact, MS is the most prevalent neurological disease in young adults (6). Early occurrence of this disease and its longterm course makes it extremely costly for the individual, family, and society; hence, the burden of disease has been a great challenge for healthcare systems (7). PwMS tolerate high levels of stress due to unpredictable nature of the disease and its related consequences $(8,9)$. Since stress has been proposed as a risk factor for MS onset and exacerbation, coping with stress is a matter of great importance for these patients (10). Coping can be defined as specific emotional, behavioral, and cognitive strategies by which individuals manage their experienced stressful life events. Lazarus et al maintain that there are various styles to cope with stress in stressful conditions that are generally categorized as 'problem-focused' and 'emotionfocused'. Problem-focused coping style consist of attempts to solve the stressful problems, and emotion-focused coping style includes the reduction of emotions originating from stressful conditions without concentration on them (11). Research findings show that PwMS are more likely to use emotional coping strategies than problem-focused coping (12). However, some researches have reported different results. For example, while Abedini et al did not find any significant difference between problem-focused and emotion-focused coping styles in PwMS and control group (13), Ahadi et al demonstrated that PwMS mainly used problem-focused coping (14).

Costa and McCrae presented the Big Five personality

(C) 2021 The Author(s); Published by Shahrekord University of Medical Sciences. This is an open-access article distributed under the terms of the Creative Commons Attribution License (http://creativecommons.org/licenses/by/4.0), which permits unrestricted use, distribution, and reproduction in any medium, provided the original work is properly cited. 
traits, also known as the five-factor model, as a taxonomy for personality traits. This theory suggests five broad dimensions commonly used to describe the human personality and psyche, and its dimensions include neuroticism, extraversion, openness to experience, conscientiousness, and agreeableness (15). Personality traits facilitate or deteriorate the psychological and physical health and adaptation by influencing the individual's interpretation of the life events (16). Personality traits are indicative of one of the influential and main factors affecting psychological functions, and therefore they affect various life qualities and therapeutic interventions (17). Studies carried out concerning personality traits of the PwMS indicate that these individuals score higher in neuroticism (18-22). Ahmadi and Mahmood Alilu specified that these patients have higher scores in neuroticism and lower scores in extraversion and agreeableness, but no difference was observed in conscientiousness and openness (23). Mohammadpur et al reported higher scores in neuroticism and conscientiousness, lower scores in extraversion and openness, and no significant variation in agreeableness of PwMS compared to healthy individuals (24). Resiliency is another personality trait, which includes the potentiality of adaptation with or overcoming the life stressors (25). Health psychologists believe that there are mediating factors between stressful life events and psychological symptoms, which cause different effects on different individuals. Resiliency can be considered as one of these factors, which helps individuals to maintain mental health despite experiencing stress or adversity $(26,27)$. Research findings show that PwMS that are more resilient experience less emotional disturbance and have a higher quality of life (QoL) (28). Therefore, given the fact that MS is a chronic and debilitating disease, and its symptoms, course, and prognosis are deeply associated with stress, and on the other hand, research on coping styles, big five factor model of personality, and resiliency have not led to consistent findings, the present study attempts to answer the question of whether there are differences in coping styles, personality traits, and resilience between PwMS and control group.

\section{Materials and Methods}

The groups (case vs. control) were matched in terms of age, sex, education, and marital status to control confounding variables; and there were no significant differences between two groups in terms of mentioned confounding variables (Table 1). According to the existing literature and $\mathrm{G}^{\star}$ Power software, $75 \mathrm{MS}$ patients $(25$ males and 50 females) were selected from the members of Tehran MS Society. There were two main inclusion criteria: patients with at least 5 years of MS diagnosis and age range of 2040 years. Patients with severe symptoms and a history of mental disorders were excluded. Then, 75 healthy subjects (25 males and 50 females) matched with PwMS group in terms of gender, marital status, and education were selected. Sampling method was based on quota sampling method in terms of gender prevalence of the disease (2:1 female:male). An informed consent was obtained from all participants and they were assured that their data would remain confidential. The instruments for the research included three questionnaires:

\section{Lazarus and Folkman Ways of Coping Questionnaire (WOCQ)}

It is a 66-item questionnaire with 4-point Likert scale $(0=$ does not apply and/or not used; $3=$ used a great deal $)$ and two subscales of emotion-focused and probe-focused coping styles. Alipour et al reported reliability coefficient of 0.81 for WOCQ in Iranian subjects (29). In this study, Cronbach's alpha coefficient was 0.88 .

NEO Five Factor Inventory-Revised (NEO-FFI)

It is a 60 -item questionnaire with 5 -point Likert scale

Table 1. Frequencies related to demographic variables of participants

\begin{tabular}{|c|c|c|c|c|c|}
\hline \multirow{2}{*}{ Variables } & & \multicolumn{3}{|c|}{ Groups } & \multirow[b]{2}{*}{$P$ value } \\
\hline & & Patients with MS & $\begin{array}{l}\text { Healthy subjects } \\
\text { (Absolute Freq.) }\end{array}$ & All subjects & \\
\hline \multirow{2}{*}{ Gender } & Male & $25(33.33 \%)$ & $25(33.33 \%)$ & $50(33.33 \%)$ & 1.0 \\
\hline & Female & $50(66.66 \%)$ & $50(66.66 \%)$ & $100(66.66 \%)$ & 1.0 \\
\hline \multirow{4}{*}{ Age range } & $20-25$ & $12(16 \%)$ & $15(20 \%)$ & $27(18 \%)$ & 0.645 \\
\hline & $26-30$ & $28(37.33 \%)$ & $26(34.66 \%)$ & $54(36 \%)$ & 0.645 \\
\hline & $31-35$ & $25(33.33 \%)$ & $22(29.33 \%)$ & $47(32 \%)$ & 0.645 \\
\hline & $36-40$ & $10(13.33 \%)$ & $12(16 \%)$ & $22(14 \%)$ & 0.645 \\
\hline \multirow{2}{*}{ Marital status } & Single & 48 (64\%) & $45(60 \%)$ & $93(62 \%)$ & 0.615 \\
\hline & Married & $27(36 \%)$ & $30(40 \%)$ & $57(38 \%)$ & 0.615 \\
\hline \multirow{4}{*}{ Education } & $3^{\text {rd }}$-grader; GS & $22(14.66 \%)$ & $10(13.33 \%)$ & $22(14.66 \%)$ & 0.597 \\
\hline & Diploma & $37(49.33 \%)$ & $33(44 \%)$ & 70 (46.66\%) & 0.597 \\
\hline & B.A/ B.S. & $19(25.33 \%)$ & $23(30.66 \%)$ & $42(28 \%)$ & 0.597 \\
\hline & $\mathrm{PhD}$ and higher & $7(9.33 \%)$ & $9(12 \%)$ & $16(10.66 \%)$ & 0.597 \\
\hline
\end{tabular}

GS, Guidance School. 
( $1=$ strongly disagree to $5=$ strongly agree), which assesses personality traits in five subscales of neuroticism, extraversion, openness to experience, agreeableness, and conscientiousness on the basis of Big Five Factor Model of Personality. Kiamehr validated this questionnaire on 380 Tehran University students and reported the coefficient resulting from the internal constancy of this questionnaire via Cronbach's alpha between $54 \%$ and $79 \%$, which is indicative of high validity of this scale to assess personality variables (30). In this study, Cronbach's alpha was obtained as $84 \%, 77 \%, 59 \%, 86 \%$, and $73 \%$ for the aforementioned subscales, respectively.

\section{Conner-Davidson Resilience Scale (CD-RISC)}

It is a short scale with 5-point Likert ranging from 0-4 ( $0=$ not true at all; $4=$ true nearly all of the time) consisting of 25 items, that yields a total score of resiliency. Mohammadi et al adapted this scale to be utilized in Iran. He performed this scale on 248 subjects and obtained the reliability as $89 \%$ via Cronbach's alpha coefficient and the validity as ranging from $41 \%$ to $64 \%$ via item-total correlation (31). In this study, Cronbach's alpha coefficient was $85 \%$.

\section{Statistical analysis method}

To analyze the data, independent $t$ test was used for resiliency variable and multivariate analysis of variance (MANOVA) was used for coping styles and personality traits variables using SPSS software version 22 .

\section{Results}

The frequencies related to demographic variables (gender, age, marital status, and education) in both case and control groups are presented in Table 1. As can be seen, matching is a proper method to control the research trend.

The groups (case vs. control) were matched in terms of age, sex, education, and marital status to control confounding variables; and there were no significant differences between two groups (Table 1).

Before performing the statistical analysis, KolmogorovSmirnov test was used, the results of which confirmed that the data distribution was normal $(P>0.05)$. Table 2 presents the mean and standard deviation for each of the research variables and subscales.
The results for the variables of coping strategies indicated that assumption of homogeneity of variance in both groups was not violated (problem-focused style: $\mathrm{F}=2.893$, $P=0.710$; emotion-focused style: $\mathrm{F}=0.169, P=0.085$ ) ( $P>0.05$ : no significance difference between variances of both groups). At least in one of the coping styles, there was a significant difference between the two groups $(P<0.05$ and $\mathrm{F}=9.15)$. The results for the variable of personality traits indicated that the assumption of homogeneity of variance in both groups was not violated (neuroticism: $\mathrm{F}=2.473$ and $P=0.109$; extraversion: $\mathrm{F}=0.17$ and $P=0.836$; openness: $\mathrm{F}=2.67$ and $P=0.131$; conscientiousness: $\mathrm{F}=0.498$ and $P=0.476$; and agreeableness: $\mathrm{F}=0.334$ and $P=0.574) \quad(P>0.05$ : no significant difference between groups in variance). At least in one of the Big Personality Factors, there was a significant difference between the two groups $(P<0.005$ and $\mathrm{F}=6.58)$.

As Table 3 indicates, there is a significant difference between the two groups in coping styles and personality traits (problem-focused styles: $\mathrm{F}=10.08$ and $P=0.001$; emotion-focused: $\mathrm{F}=6.980$ and $P=0.008$ ) (neuroticism: $\mathrm{F}=16.55$ and $P=0.001$; extraversion: $\mathrm{F}=7.993$ and $P=0.005$; conscientiousness: $\mathrm{F}=7.293$ and $P=0.008$ ). There was no significant difference between the two groups in two variables of openness $(\mathrm{F}=1.106$ and $P=0.284)$ and agreeableness $(\mathrm{F}=0.414$ and $P=0.556)$. Independent $t$ test was performed to assess the difference in resiliency levels of both groups. Also, Levene's test was performed to assess the homogeneity of variance in groups. The results showed that the assumption of homogeneity of variance

Table 2. Mean \pm SD for research variables

\begin{tabular}{lcc}
\hline \multirow{2}{*}{ Variables } & Patients with MS & Healthy subjects \\
\cline { 2 - 3 } & Mean \pm SD & Mean \pm SD \\
\hline Problem-focused & $39.84 \pm 5.79$ & $43.25 \pm 5.29$ \\
Emotion-focused & $44.53 \pm 9.13$ & $39.97 \pm 9.61$ \\
Neuroticism & $32.10 \pm 4.80$ & $27.51 \pm 6.02$ \\
Extraversion & $27.46 \pm 7.12$ & $31.66 \pm 6.75$ \\
Openness to experience & $29.64 \pm 6.53$ & $30.68 \pm 5.62$ \\
Conscientiousness & $32.98+ \pm 5.72$ & $36.35 \pm 5.02$ \\
Agreeableness & $32.72 \pm 6.85$ & $32.04 \pm 6.60$ \\
Resiliency & $68.13 \pm 13.90$ & $74.10 \pm 15.45$ \\
\hline
\end{tabular}

Table 3. Results of MANOVA for coping styles and personality traits variables

\begin{tabular}{|c|c|c|c|c|c|}
\hline Variable & Sum of squares & Df & Mean of squares & $\mathbf{F}$ & $P$ value \\
\hline Problem-focused & 591.082 & 1 & 591.082 & 10.08 & 0.001 \\
\hline Emotion-focused & 291.822 & 1 & 291.822 & 6.980 & 0.008 \\
\hline Neuroticism & 512.432 & 1 & 512.432 & 16.55 & 0.001 \\
\hline Extraversion & 389.025 & 1 & 389.025 & 7.993 & 0.005 \\
\hline Openness to experience & 45.585 & 1 & 45.585 & 1.106 & 0.286 \\
\hline Conscientiousness & 206.252 & 1 & 206.252 & 7.293 & 0.008 \\
\hline Agreeableness & 22.365 & 1 & 22.365 & 0.414 & 0.556 \\
\hline
\end{tabular}


in both groups was not violated $(\mathrm{F}=0.495, P=0.519)$ $(P>0=05$ : no significant difference between the variances of both groups).

As Table 4 indicates, the level of resiliency of PwMS and healthy subjects were significantly different $(P=0.05)$, and this level was lower for PwMS.

\section{Discussion}

The present study compared the coping styles, personality traits, and resiliency in PwMS and healthy subjects. The results showed that there were statistically significant differences between the two groups in all the variables. According to the data, PwMS used emotion-focused style more often compared to healthy group, which is in line with the results of the majority of other studies (12). The coping style is a matter of crucial importance in patients facing a chronic disease, such as MS (32). Although PwMS often experience relatively symptom-free periods in the course of their disease, research findings suggest that their coping strategies differ from general population (12). PwMS are more likely to act passively when facing with stress, which does not improve over the time (33). Although the use of emotion-focused strategies can help PwMS regulate their negative feelings and it is to some extent a useful strategy in adjustment with MS (34), greater reliance on emotionfocused strategies and less use of problem-focused coping are related to poorer psychological adjustment in these patients (35). The results on personality traits, consistent with most of other studies (18-22), indicated that PwMS show higher levels of neuroticism and lower levels of extraversion, agreeableness, and conscientiousness in comparison with general population. It seems that this maladaptive personality configuration, known as "type D personality", which is specified by high neuroticism, low extraversion, and to some extent low conscientiousness and agreeableness (36), is somehow related to MS and other neurocognitive diseases (18). It means that these patients are more irritable, distressed, and anxious, and less outgoing and assertive than general population; but the cause and ways of interaction between MS and this personality configuration remain unclear. Finally, our results showed that resiliency levels in PwMS are significantly lower than healthy group. These results are consistent with the data suggesting that PwMS are less resilient than general population and even people with other chronic diseases (37). Resilience is characterized in terms of protective and risk factors (38); it seems that the interplay between risk and protective factors in PwMS leads to low levels of resiliency in them. Risk factors such as frequent use of avoidance and emotional coping (e.g. mental and behavioral disengagement, venting emotions and denial), MS symptoms (e.g. fatigue and pain), and MS-related stress itself, along with lack of protective factors such as low extraversion and lower reliance on problem-focused strategies in PwMS, lead to low levels of resiliency in these patients (39). Therefore, it seems that enhancing the resiliency in PwMS through psychoeducation programs or resiliency-focused treatments, can help these patients experience higher quality of life and better health status.

\section{Conclusion}

This study compared coping styles, personality traits, and resiliency in PwMS. Caring for MS patients requires more awareness of various coping styles, personality traits, and resiliency variables. The findings of this study indicated that PwMS, compared to healthy individuals, are more likely to use emotional coping strategies in facing with stress, which probably helps them regulate their negative feelings in short term. Also, the results confirmed that a maladaptive personality configuration, which is specified by high neuroticism, along with low extraversion, conscientiousness, and agreeableness are somehow related to MS. Finally, it seems that the interplay between risk and protective factors in PwMS can lead to low levels of resiliency in them.

\section{Limitations}

Since the design of current study is retrospective, it is impossible to infer causality or the ways in which the variables interact with MS. Therefore, we suggest studies that explore the impact of protective/risk factors investigated in this study, or other factors which may affect the disease course and its physical or psychological manifestations.

\section{Conflict of Interests}

The authors declared no conflict of interests.

\section{Ethical Approval}

All the experiments were conducted in accordance with the ethical guidelines on human experimentation. The Research Ethics Committee of Kharazmi University, Tehran, Iran approved the study protocol (IR.KHU.REC.1398.009).

\section{Acknowledgments}

This study has been extracted from the BS dissertation of Amir Mahdi Katani at Kharazmi University (approve No. 800/101). The authors wish to thank all the colleagues from Kharazmi University of Tehran and Shahrekord University of Medical Sciences. We also thank all the staff and patients of Tehran MS Society, who kindly supported the research.

References

1. Xie ZX, Zhang HL, Wu XJ, Zhu J, Ma DH, Jin T. Role of the

Table 4. Results from independent $t$ test for resiliency variable

\begin{tabular}{lccccccc}
\hline Group & N & M & Difference in mean & Standard error difference & df & T & Mutual significance \\
\hline Patients with MS & 75 & 63.13 & -10.47 & 4.480 & 148 & -2.32 & 0.021 \\
Healthy subjects & 75 & 73.60 & & & & \\
\hline
\end{tabular}


immunogenic and tolerogenic subsets of dendritic cells in multiple sclerosis. Mediators Inflamm. 2015;2015:513295. doi: 10.1155/2015/513295.

2. Henry A, Tourbah A, Camus G, Deschamps R, Mailhan L, Castex C, et al. Anxiety and depression in patients with multiple sclerosis: the mediating effects of perceived social support. Mult Scler Relat Disord. 2019;27:46-51. doi: 10.1016/j.msard.2018.09.039.

3. Hunter SF. Overview and diagnosis of multiple sclerosis. Am J Manag Care. 2016;22(6 Suppl):S141-50.

4. Azami M, YektaKooshali MH, Shohani M, Khorshidi A, Mahmudi L. Epidemiology of multiple sclerosis in Iran: a systematic review and meta-analysis. PLoS One. 2019;14(4):e0214738. doi: 10.1371/journal.pone.0214738.

5. Hosseinzadeh A, Baneshi MR, Sedighi B, Kermanchi J, Haghdoost AA. Incidence of multiple sclerosis in Iran: a nationwide, population-based study. Public Health. 2019;175:138-44. doi: 10.1016/j.puhe.2019.07.013.

6. Stenager E. A global perspective on the burden of multiple sclerosis. Lancet Neurol. 2019;18(3):227-8. doi: 10.1016/ s1474-4422(18)30498-8.

7. Wallin MT, Culpepper WJ, Nichols E, Bhutta ZA, Gebrehiwot TT, Hay SI, et al. Global, regional, and national burden of multiple sclerosis 1990-2016: a systematic analysis for the Global Burden of Disease Study 2016. Lancet Neurol. 2019;18(3):269-85. doi: 10.1016/s14744422(18)30443-5.

8. Kobelt G, Thompson A, Berg J, Gannedahl M, Eriksson J. New insights into the burden and costs of multiple sclerosis in Europe. Mult Scler. 2017;23(8):1123-36. doi: $10.1177 / 1352458517694432$.

9. Skierlo S, Rommer PS, Zettl UK. Symptomatic treatment in multiple sclerosis-interim analysis of a nationwide registry. Acta Neurol Scand. 2017;135(4):394-9. doi: 10.1111/ ane.12612.

10. Briones-Buixassa L, Milà R, J MA, Bufill E, Olaya B, Arrufat FX. Stress and multiple sclerosis: a systematic review considering potential moderating and mediating factors and methods of assessing stress. Health Psychol Open. 2015;2(2):2055102915612271. doi: $10.1177 / 2055102915612271$.

11. Lazarus RS, Folkman S. Stress, Appraisal, and Coping. Springer Publishing Company; 1984.

12. Keramat Kar M, Whitehead L, Smith CM. Characteristics and correlates of coping with multiple sclerosis: a systematic review. Disabil Rehabil. 2019;41(3):250-64. doi: 10.1080/09638288.2017.1387295.

13. Abedini SM, Montazeri S, Khalatbari J. Comparison between styles of coping with stress in patient with multiple sclerosis and healthy people in the east of Mazandaran. J Mazandaran Univ Med Sci. 2012;22(94):71-7. [Persian].

14. Ahadi H, Delavar A, Rostami AM. Comparing coping styles in MS patients and healthy subjects. Procedia Soc Behav Sci. 2014;116:3454-7. doi: 10.1016/j.sbspro.2014.01.782.

15. Costa J, PAUL T. of personality theories: Theoretical contexts for the five-factor model. The five-factor model of personality: Theoretical perspectives. 1996;51.

16. Grant S, Langan-Fox J, Anglim J. The big five traits as predictors of subjective and psychological wellbeing. Psychol Rep. 2009;105(1):205-31. doi: 10.2466/ pr0.105.1.205-231.

17. Nada MA, Abd El-Mawella SM, Bayoumy HA, El Sirafy
MN. Personality trait and coping strategies in multiple sclerosis: neuropsychological and radiological correlation. Egypt J Neurol Psychiatr Neurosurg. 2011;48(1):71-8.

18. Benedict RH, Priore RL, Miller C, Munschauer F, Jacobs L. Personality disorder in multiple sclerosis correlates with cognitive impairment. J Neuropsychiatry Clin Neurosci. 2001;13(1):70-6. doi: 10.1176/jnp.13.1.70.

19. Bruce JM, Lynch SG. Personality traits in multiple sclerosis: association with mood and anxiety disorders. J Psychosom Res. 2011;70(5):479-85. doi: 10.1016/j. jpsychores.2010.12.010.

20. Khodarahimi S, Rasti A. The roles of fatigue, depression, and Big Five Personality traits in males with and without multiple sclerosis disease. Clin Salud. 2015;26(2):91-6. doi: 10.1016/j.clysa.2015.03.002.

21. Penner IK, Bechtel N, Raselli C, Stöcklin M, Opwis K, Kappos L, et al. Fatigue in multiple sclerosis: relation to depression, physical impairment, personality and action control. Mult Scler. 2007;13(9):1161-7. doi: 10.1177/1352458507079267.

22. Sindermann C, Saliger J, Nielsen J, Karbe H, Markett S, Stavrou M, et al. Personality and primary emotional traits: disentangling multiple sclerosis related fatigue and depression. Arch Clin Neuropsychol. 2018;33(5):552-61. doi: 10.1093/arclin/acx104.

23. Ahmadi P, Mahmood Alilu S. Comparison of personality factors in multiple sclerosis patients and healthy subjects by five factor model. Med J Tabriz Univ Med Sci. 2012;34(4):712. [Persian].

24. Moahmmad Pour K, Kafie SM, Hatamiyan HR, Rezaei S, Hosseininezhad M. Comparison of psychological symptoms and personality characteristics between patients with multiple sclerosis and normal matched people. Jundishapur Sci Med J. 2014;13(3):301-14. [Persian].

25. van Kessel G. The ability of older people to overcome adversity: a review of the resilience concept. Geriatr Nurs. 2013;34(2):122-7. doi: 10.1016/j.gerinurse.2012.12.011.

26. Kalisch R, Baker DG, Basten U, Boks MP, Bonanno GA, Brummelman E, et al. The resilience framework as a strategy to combat stress-related disorders. Nat Hum Behav. 2017;1(11):784-90. doi: 10.1038/s41562-017-0200-8.

27. Shrivastava A, Desousa A. Resilience: a psychobiological construct for psychiatric disorders. Indian J Psychiatry. 2016;58(1):38-43. doi: 10.4103/0019-5545.174365.

28. Nakazawa K, Noda T, Ichikura K, Okamoto T, Takahashi $\mathrm{Y}$, Yamamura T, et al. Resilience and depression/anxiety symptoms in multiple sclerosis and neuromyelitis optica spectrum disorder. Mult Scler Relat Disord. 2018;25:30915. doi: 10.1016/j.msard.2018.08.023.

29. Alipour A, Hashemi T, Babapour J, Tousi F. Relationship between coping strategies and happiness among university students. J Psychol (Tabriz University). 2010;5(18):71-86. [Persian].

30. Kiamehr J. Normalization of NEO Personality Inventory (NEOPIR) and Exploration of its 'Factor Analysis in the Students of University of Tehran [dissertation]. Allameh Tabataba’i University; 2002. [Persian].

31. Mohammadi M, Jazayeri AR, Rafiei AH, Jokar B, Pourshahbaz A. Study of the resiliency factors in people at risk of drug abuse. Journal of Modern Psychological Researches. 2006;1(2-3):193-214.

32. Goretti B, Portaccio E, Zipoli V, Razzolini L, Amato MP. Coping strategies, cognitive impairment, psychological 
variables and their relationship with quality of life in multiple sclerosis. Neurol Sci. 2010;31(Suppl 2):S227-30. doi: 10.1007/s10072-010-0372-8.

33. Lode K, Bru E, Klevan G, Myhr KM, Nyland H, Larsen JP. Coping with multiple sclerosis: a 5-year follow-up study. Acta Neurol Scand. 2010;122(5):336-42. doi: 10.1111/j.1600-0404.2009.01313.x.

34. McCabe MP, McKern S, McDonald E. Coping and psychological adjustment among people with multiple sclerosis. J Psychosom Res. 2004;56(3):355-61. doi: 10.1016/ s0022-3999(03)00132-6.

35. Pakenham KI. Adjustment to multiple sclerosis: application of a stress and coping model. Health Psychol. 1999;18(4):383-92. doi: 10.1037//0278-6133.18.4.383.

36. Chapman BP, Duberstein PR, Lyness JM. The distressed personality type: replicability and general health associations. Eur J Pers. 2007;21(7):911-29. doi: 10.1002/ per.645.

37. Terrill AL, Molton IR, Ehde DM, Amtmann D, Bombardier $\mathrm{CH}$, Smith $\mathrm{AE}$, et al. Resilience, age, and perceived symptoms in persons with long-term physical disabilities. J Health Psychol. 2016;21(5):640-9. doi: $10.1177 / 1359105314532973$

38. Kumpfer KL. Factors and processes contributing to resilience. In: Glantz MD, Johnson JL, eds. Resilience and Development: Positive Life Adaptations. Boston, MA: Springer; 2002. p. 179-224. doi: 10.1007/0-306-47167-1_9.

39. Kasser SL, Zia A. Mediating role of resilience on quality of life in individuals with multiple sclerosis: a structural equation modeling approach. Arch Phys Med Rehabil. 2020;101(7):1152-61. doi: 10.1016/j.apmr.2020.02.010. 